\title{
Mediating Effects of Emotional Regulation on Depression and Life Satisfaction of College Students
}

\author{
Ok-Ju, Lee1)
}

\begin{abstract}
The purpose of this study is to examine the mediating effect of emotion regulation on the relationship between depression and life satisfaction of college students. The subjects of this study consisted of 270 males $(43 \%)$ and 102 females (37.8\%) and 52 non-responders (19.3\%) who take the liberal arts at $\mathrm{K}$ University in Seoul. By grade, 93 students (34.4\%) in first grade, 66 students $(24.4 \%)$ in second grade, 38 students $(14.1 \%)$ in third grade, 21 students $(7.8 \%)$ in fourth grade, and 52 non-responders $(19.3 \%)$ participated. Correlation analysis and regression analysis were conducted. The analysis results are as follows. First, as a result of analyzing the correlation between variables, depression was negatively significant with emotion control, life satisfaction. Emotional control and life satisfaction were statistically significant at .001 level. Second, emotional regulation plays a role as a mediator in the process of depression affecting life satisfaction. And when emotion regulation was controlled, the explanatory power of depression was significant. Based on these results, it is expected that the satisfaction of life through college students with depressive tendencies can be improved through emotional control.
\end{abstract}

Keywords: Depression, Emotional, Regulation, Satisfaction of Life, Mediating, Effect

\section{Introduction}

Recently, there are increasing concerns regarding the mental health of college students. Based on the data from the Korean Council for University Education[1], Korean college students are dealing with psychological difficulties related to personality, depression, anxiety, or relationship. A survey on mental health of college student showed that significant proportion of college students are facing difficulties with mal-adaptability[2]. Based on the Beck Depression Index (BDI), 9.7\% of the total is reported to experience 'severe depression' and require immediate counseling and treatment. Also, Beck Anxiety Inventory (BAI) showed that $28.4 \%$ of the total college students are suffering from 'severe anxiety' taking up majority portion. Although the number of college students visiting campus counseling center increased $24.22 \%$ compared to last year, immediate counseling is yet to be provided to these students[3].

Received(September 19, 2019), Review Result(1st: October 16, 2019, 2nd: November 26, 2019), Accepted(January 30, 2020)

1) (Student) 04310 Dept. Education, Sookmyung Women's University, 100, Cheongpa-ro 47-gil, Yongsan-gu, Seoul, Korea

email: leeoj66@naver.com 
Most college students falling within the boundary of late adolescence to early adulthood are faced with a stressful environment involving sudden freedom of time compared to their tightly scheduled high-school years, need to adjust to new campus life, uncertainty of future, pressure from resume building, and concern for youth unemployment rate as well as high tuitions fees[4]. Such abrupt changes to their environment seem to cause psychological stress in the college students. Depression among college students is twice as high as the prevalence of the depression among working population of the same age group[5]. Depression from adolescence not only leads higher likelihood of persisting into adulthood but may also leads to other major psychological disorders[6] as well as increased suicidal attitude. Depressed college students are causing life problems like smartphone addiction[7]. Thus, it is important that degree of depression be reduced[8].

Emotion is a process of complicated psychological system controlling various processes such as affective, cognitive, expressive, and physiological process. It functions by providing motivational and physiological energy to react to important stimuli and responsible for preparing and continuing a behavior by concentrating on specific stimulus and controlling thinking process[9]. Emotional regulation is also known as one of the elements affecting life satisfaction and considered a crucial element for providing better understanding functions and health in humans[10]. Many researchers have stated emotional regulation as an important element determining well-being along with healthy and successful functioning of each individual. Gaining emotional regulation may act as a positive defensive mechanism for college students by supporting individual adjustment and well-being through buffering negative influence exerted when they are exposed to various difficulties[11]. Emotional regulation also influences individual maturity, independence, creativeness, vigor, social capability, peer popularity, and successful execution of cognitive tasks[12]. Emotion control also affects self-respect which refers to self-evaluation and feelings on a certain characteristic possessed by an individual. In fact, emotional processes such as emotional recognition and emotional regulation bear significant relation with self-respect[13] and emotional regulation is known to exert influence on adjustment process and happiness of individuals[14]. College students who are in their late adolescence phase where their control over emotion becomes more sophisticated and such strategies become internalized through socialization. It is crucial for individuals in adolescence phase to gain control over their emotion as they will be subject to emotional anxiety and various difficulties resulting from such anxiety[15].

On top of emotional maladjustment such as depression, college students of Korea were ranked 10 from the bottom on life satisfaction, an index reflecting happiness, among 47 
nations[16]. Life satisfaction is an important element for domestic researches conducted on mental health of children as it is considered to include a positive adaptability to an environment and can provide better understanding to issues related to mal-adaptation among college students. Life satisfaction is highly related to maladaptation elements such as depression. There is a strong negative correlation existing between depression and life satisfaction[17] and lethargic state resulting from depression may leads to various problems across all aspects of life. Life stress resulting from decreased life satisfaction is believed to be the major reason for suicides among college students. The continuous sense of discouragement resulting by failing to counteract such stress leads to suicidal thoughts and impulsive suicidal attempts[18].

Thus, this study seeks a way to increase life satisfaction among college students by analyzing mediating effect of emotional regulation in depression among college students and life satisfaction. The result of this study is expected to contribute to the development of more effective treatment for counselee with depression who visit college counseling center.

\section{Method}

\subsection{Subject}

This study was conducted on college students taking liberal arts in K University located in Seoul. Total of 270 subjects participated in this study; 116 males (43\%), 102 females (37.8\%), and 52 non-responders (19.3\%). When classified based on college years, 93 were freshmen $(34.4 \%), 66$ were sophomores $(24.4 \%), 38$ were junior $(14.1 \%), 21$ were senior, and $52(9.3 \%)$ were non-responders.

\subsection{Measurement Scale}

\subsubsection{Depression}

In order to measure the degree of depression experienced by subjects, the study utilized Korean version of Beck Depression Inventory (BDI) standardized into Korean by Lee and Song[19] from the original version established by Beck. Korean version of BDI is created as a self-reporting survey consisting of 21 questions including 4 sub-factors of 'Guilt/Self-Hate,' 'Negative Self-Reflection/Delayed Psychomotor Activity,' 'Physical Aspect,' and 'Emotional 
Expression/Negative Cognition.' Each question will be given a score from 0 to 3 making the total score ranging from 0 to 63 and each score range determines the state of subject; Normal (0 9), Mild Depression (10 15), Moderate Depression (16 23), and Severe Depression (Higher than 24). The study conducted by Lee and Song[18] showed Chronbach's coefficient alpha of .98 and the value obtained from this study was .87 .

\subsubsection{Life Satisfaction}

Measurement on life satisfaction was established by using life satisfaction in personal space utilized in the Study on support plan for improving mental health of child/adolescents III[20] and adjusting it to target college students. The survey consisted of 8 questions in total including topics such as relationship with parents, friends, professors, economic standard of living, school life, grades, and satisfaction on health condition. Each question is constructed with 4-point Likert-type scale on which higher score can be interpreted as higher satisfaction. Based on the data from National Youth Policy Institute, the reliability coefficient was .874 while the result from this study showed a coefficient of .788 .

\subsubsection{Emotional Regulation}

Measurement on emotional regulation was established using emotional regulation of positive factor utilized in the Study on support plan for improving mental health of child/adolescents III[20]. The question consists of 3 sentences; 'I can concentrate on studies or tasks without being swayed by emotion,' 'I do not get discouraged when I am sad or faced with hardships,' and 'I have control over my emotion even if I am angry or upset.' Each sentence is assigned with 4-point Likert-type scale on which higher score means stronger emotional regulation. Based on the data from National Youth Policy Institute, reliability coefficient was .837 while the result from this study showed coefficient of .864 .

\subsection{Analysis of Materials}

This study proceeded with correlational study in order to determine the relationship between depression, emotional regulation, and life satisfaction. Additionally, to analyze the meditating effect of emotional regulation has on the influence of depression over life satisfaction, regression analysis had been conducted. SPSS 18.0 was used for statistic examination. 


\section{Result of Research}

Correlational analysis was conducted in order to determine the relationship between 3 major variables of this study such as depression, emotional regulation, and life satisfaction. The result is as follows.

[Table 1] Correlation among variables

\begin{tabular}{lccccccc}
\hline \hline Variable & 1 & 2 & 3 & 4 & 5 & 6 & 7 \\
\hline 1. Depression & & & & & & \\
2. Guilt/Self-Hate & $.86^{* * *}$ & & & & & \\
$\begin{array}{l}\text { 3. Negative Self-Reflection/ } \\
\text { Delayed Psychomotor Activity }\end{array}$ & $.82^{* * *}$ & $.60^{* * *}$ & & & & & \\
4. Physical Aspect & $.71^{* * *}$ & $.44^{* * *}$ & $.49^{* * *}$ & & \\
$\begin{array}{l}\text { 5. Emotional Expression/ } \\
\text { Negative Cognition }\end{array}$ & $.78^{* * *}$ & $.57^{* * *}$ & $.53^{* * *}$ & $.43^{* * *}$ & & \\
6. Emotional regulation & $-.50^{* * *}$ & $-.45^{* * *}$ & $-.41^{* * *}$ & $-.29^{* * *}$ & $-.45^{* * *}$ & \\
7. Life Satisfaction & $-.50^{* * *}$ & $-.43^{* * *}$ & $-.43^{* * *}$ & $-.33^{* * *}$ & $-.38^{* * *}$ & $.42^{* * *}$ \\
\hline & & & & & & \\
\hline
\end{tabular}

Based on the results on [Table 1], depression had a negative significant correlation with the value of .001 with emotional regulation $(\mathrm{r}=.50)$ and life satisfaction $(\mathrm{r}=.50)$. Emotional regulation and life satisfaction $(\mathrm{r}=.42)$ had a positive significant correlation with the value of .001 . By examining the relationship between emotional regulation and subfactors of depression, it was determined that all subfactors including 'Guilt/Self-Hate $(\mathrm{r}=.45)$, ' 'Negative Self-Reflection/Delayed Psychomotor Activity ( $\mathrm{r}=.41)$,' 'Physical Aspect ( $\mathrm{r}=.29)$, and 'Emotional Expression/Negative Cognition $(r=.45)^{\prime}$ was shown to have negative significant correlation with the value of .001. By examining life satisfaction and subfactors of depression, it was determined that all subfactors including 'Guilt/Self-Hate ( $\mathrm{r}=.43)$,' 'Negative Self-Reflection/Delayed Psychomotor Activity ( $\mathrm{r}=.43)$,' 'Physical Aspect ( $\mathrm{r}=.33)$, and 'Emotional Expression/Negative Cognition $(\mathrm{r}=.38)^{\prime}$ was shown to have negative significant correlation with the value of .001 . 
[Table 2] Regression Analysis of Depression and Emotional Regulation on Life Satisfaction

\begin{tabular}{cllccccc}
\hline \hline $\begin{array}{c}\text { Investigation } \\
\text { Phase }\end{array}$ & \multicolumn{1}{c}{$\begin{array}{c}\text { Independent } \\
\text { Variable }\end{array}$} & $\begin{array}{c}\text { Dependent } \\
\text { Variable }\end{array}$ & B & SE & t & R2 & F \\
\hline 1st Phase & Depression & $\begin{array}{l}\text { Emotional } \\
\text { Regulation }\end{array}$ & -3.22 & 0.35 & $-9.20^{* * *}$ & 0.249 & $86.62^{* * *}$ \\
\hline 2nd Phase & Depression & Life Satisfaction & -6.32 & 0.68 & $-9.24^{* * *}$ & 0.252 & $85.39^{* * *}$ \\
\hline \multirow{2}{*}{ 3rd Phase } & Depression & Life Satisfaction & -4.90 & 0.77 & $-6.36^{* * *}$ & & \\
\cline { 2 - 6 } & $\begin{array}{l}\text { Emotional } \\
\text { Regulation }\end{array}$ & & .45 & 0.12 & $3.80^{* * *}$ & & \\
\hline & & & & & sobel test & $\mathrm{z}=-3.52(\mathrm{p}<.001)$
\end{tabular}

The results of 3rd phase analysis to determine the mediating effect of emotional regulation on relationship between depression and life satisfaction are as seen in [Table 2]. Firstly, the result showed that depression, an independent variable, had significant effect on life satisfaction, a dependent variable $(\beta=3.22 \mathrm{p}<.001)$. Secondly, emotional regulation, a mediating variable, is shown to have significant effect on life satisfaction, a dependent variable ( $\beta=.45$ $\mathrm{p}<.001$ ). Based on these results, it can be determined that emotional regulation meets 3 conditions necessary for confirming mediating effect. Lastly, despite the $\beta$ value of depression on satisfaction was measured as -6.32 in 2 nd phase, the value changed to $\beta-4.90$ in 3rd phase when emotional regulation, a mediating variable, was controlled. Such result indicates that emotional regulation does play a role as a mediating variable in relationship between depression and life satisfaction. Additionally, mediating effect was confirmed as explanatory power of depression was significant when emotional regulation was under control. The result of Sobel test conducted to verify the mediating effect showed $\mathrm{z}$ value of $-3.52 \quad(\mathrm{p}<.001)$ confirming the significance of partial mediating effect. As the result of Durbin-Watson test showed a value close to 2 with the number of 2.082, this study confirms the significance of mediating effect.

\section{Discussion}

This study is conducted to analyze the mediating effect of emotional regulation on the relationship between depression and life satisfaction experienced in college students. In order to establish a result, correlation analysis was conducted on depression, emotional regulation, and life satisfaction and regression analysis was conducted to analyze whether emotional regulation 
have mediating effect on relationship between depression and life satisfaction.

Firstly, the result of correlation analysis showed that depression had negative significant correlation with emotional regulation and life satisfaction. Such result supports the findings established by precedent studies[17] that depression has a strong negative correlation with life satisfaction. The result of studies conducted by Park \& Hah[17] showed correlation coefficient of -.37 between depression and life satisfaction. The result of this study indicated stronger negative correlation with the value of -.50. Findings established by other studies conducted on students in middle school and high school also confirmed strong negative correlation between depression and school class adaptability and relationship with others with the value of -.258 and -.467 respectively[21]. Thus, the result of this study supports those established by precedent studies.

Secondly, emotional regulation and life satisfaction is shown to have a positive correlation. The result of studies on students in middle and high school conducted by Jang \& Shin[22] showed correlation coefficient of .447 and .524 in relationship between school satisfaction and emotional regulation indicating the presence of strong positive correlation. The findings of the study done by Hyon[12] which showed correlation efficient or -.50 in relationship between difficulties in emotional regulation and happiness indicating the presence of strong negative correlation suggests that better emotional regulation leads to happiness. Considering the findings of this study showing the existence of positive correlation between emotional regulation and life satisfaction with the correlation coefficient of .42 , it can be concluded that the findings of this study supports those established by precedent studies.

Thirdly, emotional regulation is shown to have a partial mediating effect on relationship between depression and life satisfaction. Such finding supports the result of precedent study conducted by Kim \& Song[23] which showed that both adaptive and cognitive emotional regulation improves positive emotion while reducing negative emotion by exerting indirect effect on depression. Also, the findings of this study support the result of the study conducted by Kim \& Lee[21] which suggested that depression exerts significant influence on individual's adaptability to school life.

The result of this study suggests that improvement in life satisfaction can be expected by strengthening emotional regulation capability in college students going through depression. Life satisfaction in college students is a crucial concept as it includes school satisfaction and allows students to take more proactive approach in making better preparation for their general life and future. It is necessary to take proactive approach in establishing measures to improve emotional regulation as a major variable that can enhance life satisfaction in college students. 


\section{References}

[1] Korean Council for University Education, Overcoming Psychological Crisis and Character Development of College Students, 57th University Education Forum, (2018), March 30; Seoul, Korea, pp.27-50.

[2] Counseling Council for University Student, National University Mental Health Survey, (2017), pp.1-369.

[3] http://weekly.khan.co.kr/khnm.html?mode=view\&code=115\&artid=201503241318071, March 24 (2015)

[4] Y. J. Choi, Stress, suicidal ideation, and protective factors in college students, Studies on Korean Youth, (2012), Vol.23, No.3, pp.77-104, UCI: G704-001385.2012.23.3.001.

[5] K. Park, The moderating and mediating effects of problem solving and evaluative concerns perfectionism on the relationship between negative life stress and depression, Korean Journal of Health Psychology, (2004), Vol.9, No,2, pp.265-283, UCI: G704-000533.2004.9.2.006.

[6] E. H. Lee, Life stress and depressive symptoms among college students: testing for moderating effects of coping style with structural equation, Korean Journal of Health Psychology, (2004), Vol.9, No.1, pp.25-52, UCI: G704-000533.2004.9.1.009.

[7] S. M. Kim, H. J. Huh, H. Cho, M. Kwon, J. H. Choi, H. J. Ahn, S. W. Lee, Y. J. Kim, \& D. J. Kim, The Effect of Depression, Impulsivity, and Resilience on Smartphone Addiction in University Students, Journal of Neuropsychiatry Association, (2014), Vol.53, No.4, pp.214-220, DOI: 10.4306/jknpa.2014.53.4.214.

[8] S. K. Kahng, Does Depression Predict Suicide? : Gender and Age Difference in the Relationship between Depression and Suicidal Attitudes, Korean Journal of Social Welfare Studies, (2010), Vol.41, No.2, pp.67-100, DOI:10.16999/kasws.2010.41.2.67.

[9] R. Pekrun, The control-value theory of achievement emotions: Assumptions, corollaries and implications for educational research and practice, Educational Psychology Review, (2006), Vol.18, pp.315- 341, https://doi.org/10.1007/s10648-006-9029-9.

[10] J. J. Gross, Emotion Regulation: Past, Present, Future, Cognition and Emotion, (1999), Vol.13, No.5, pp.551-573, DOI: https://doi.org/10.1080/026999399379186

[11] J. Y. Lee, The Effect of Cognitive Emotion Regulation and Stress Coping Strategy on Psychological Well-Being of College Students: Mediated by Social Support, Daegu University, Doctoral Dissertation, (2012)

[12] C. S. Hyon, The Mediating Effects of Social Support and Empowerment on the Relationship Between Emotional Regulation and Happiness, Hongik University, Doctoral Dissertation, (2010)

[13] J. Ciarrochi, A. Chan, \& P. Caputi, A critical evaluation of the emotional intelligence construct, Personality and Individual Differences, (2000), Vol.28, No.3, pp.539-561.

[14] G. A. Bonanno, Emotion self-regulation. In J. J. Mayne, \& G. A. Bonanno (Eds.), Emotions : Current issues and future directions, New York : Guilford, (2001)

[15] C. M. Aldwin, Stress, coping and development: An integrative perspective, New York: Guilford Press, (1994) 
[16] E. Diener, S. Oishi, \& R. E. Lucas, Personality, culture, and subjective well-being, Annual Reviews of Psychology, (2003), Vol.54, pp.403-426.

[17] K. H. Park, \& Y. S. Hah, Depression, Self-efficacy, Life Satisfaction and Coping Behaviors of University Students, The Korean Journal of Stress Research, (2007), Vol.15, No.1, pp.17-25.

[18] S. Y. Kim, \& K. M. Chae, The Effects of University Student's Life Stress on Suicidal Ideation: The Moderating Effects of Perceived Social Support and the Meaning of Life, Journal of Human Understanding and Counseling, (2013), Vol.34, No.1, pp.1-13.

[19] Y. H. Lee, \& J. Y. Song, A study of the reliability and the validity of the BDI, SDS, and MMPI-D scales, Korean Journal of Clinical Psychology, (1991), Vol.10, No.1, pp.98-113.

[20] National Youth Policy Institute, A study on mental health improvement policy for children and adolescents, (2013)

[21] A. Y. Kim, \& M. H. Lee, Structural Relationships Among Adolescents` Psychological Need Satisfaction, Depressive Tendency, and School Adjustment in Middle- and Highschool, The Korean Journal of Educational Psychology, (2008), Vol.22, No.2, pp.423-441.

[22] D. H. Jang, \& H. J. Shin, The Mediating Effects of Child and Adolescent Stress on Life Satisfaction: Elementary, Middle and High School Group Analysis through Emotion Regulation and Family Intimacy, The Society for Open Parent Education: SOPE, (2017), Vol.9, No.4, pp.191-216.

[23] Y. E. Kim, \& W. Y. Song, The Influence of Emotional Awareness of Adolescents on Depression and Psychological Well-being: The Mediating Effects of Cognitive Emotion Regulation, The Korean Journal of Health Psychology, (2017), Vol.22, No.4, pp.1075-1093. 